\title{
Preventing Foodborne Illness: Cyclosporiasis ${ }^{1}$
}

\author{
Christopher R. Pabst, Jaysankar De, Renée Goodrich Schneider, and Keith R. Schneider²
}

\section{What is cyclosporiasis?}

Cyclosporiasis is an intestinal illness caused by the microscopic parasite Cyclospora cayetanensis. People can become infected with Cyclospora by consuming food, such as fresh produce, that has come in contact with water contaminated with the parasite. People living or traveling in countries where cyclosporiasis is endemic may be at increased risk for infection (CDC 2018b). Cyclosporiasis was once considered "traveler's diarrhea" for its prevalence among visitors to regions where the parasite is endemic. This illness has been reported annually in the United States since 1995. In 2018, 2,299 laboratory-confirmed cases of cyclosporiasis in people who became ill during May-August without a history of international travel were reported to the CDC by 33 states (CDC 2018a). This number is markedly higher than the numbers of cases reported for the same period in 2016 and 2017. The increase in prevalence seen in recent years may be due in part to changes in diagnostic testing practices-namely, increased use of a multiplex molecular assay to examine stool specimens.

\section{What is Cyclospora cayetanensis?}

\section{Cyclospora is a microscopic, single-celled, intestinal,} obligate (requiring a host for completion of its life cycle) protozoan parasite (Ortega and Sanchez 2010). These organisms produce a thick-walled spore called an oocyst. The oocyst protects the developing zygote and makes them resistant to disinfectants and capable of surviving outside the host for extended periods. Among several species of Cyclospora, only C. cayetanensis causes illness in humans. The first reports of gastrointestinal illness caused by Cyclospora were in the 1980s and early 1990s. Many of these early cases were travelers returning from developing countries or tropical locations (Mansfield and Gajadhar 2004). Since the late 1990s C. cayetanensis has increasingly been associated with imported produce (Mansfield and Gajadhar 2004). C. cayetanensis is not limited to imported foods. In July, FDA found the first confirmed evidence of the presence of C. cayetanensis in domestic produce when two cilantro samples tested positive for the parasite.

\section{How does Cyclospora cayetanensis spread?}

It is well known that Cyclospora multiplies in the small intestine of humans, but the full host range of C. cayetanensis is currently unknown. Oocysts are excreted in the feces of the infected individuals, sporulate, and infect other individuals or animals. Chimpanzees and other primates are believed to serve as potential reservoirs for the parasite (Mansfield and Gajadhar 2004; Ortega and Sanchez 2010). Humans become infested by ingesting sporulated oocysts. These oocysts can be found in soil, or more frequently in contaminated food and water (Mansfield and Gajadhar 2004). C. cayetanensis then replicates in the host's intestine and continues to spread to nearby cells. It is in this selflimiting (short-lived) stage that most of the symptoms associated with this parasite are manifested (Ortega and Sanchez 2010). Foods can be contaminated with Cyclospora

\footnotetext{
1. This document is FSHN0519, one of a series of the Food Science and Human Nutrition Department, UF/IFAS Extension. Original publication date September 2005. Revised March 2015 and March 2019. Visit the EDIS website at https://edis.ifas.ufledu for the currently supported version of this publication.
}

2. Christopher R. Pabst, graduate student; Jaysankar De, postdoctoral research associate; Renée M. Goodrich Schneider, professor; and Keith R. Schneider, professor; Food Science and Human Nutrition Department; UF/IFAS Extension, Gainesville, FL 32611.

The Institute of Food and Agricultural Sciences (IFAS) is an Equal Opportunity Institution authorized to provide research, educational information and other services only to individuals and institutions that function with non-discrimination with respect to race, creed, color, religion, age, disability, sex, sexual orientation, marital status, national origin, political opinions or affiliations. For more information on obtaining other UF/IFAS Extension publications, contact your county's UF/IFAS Extension office. 
oocysts when exposed to feces of infected individuals (Hall, Jones, and Herwaldt 2011). At regular temperatures, after one to two weeks, shed oocysts sporulate and become "activated" (i.e., infectious). If consumed through contaminated food or water, the disease will then spread to the new host. Due to this lag time in infectivity, direct person-to-person contamination is unlikely (Ortega and Sanchez 2010).

Environmental factors influence the time required for shedding oocysts to become pathogenic (sporulate), and these conditions can vary regionally and seasonally (Chacín-Bonilla 2010; 2017). Depending on region, a marked seasonal pattern can be seen with C. cayetanensis. In the United States, positive cases are usually found between March and August with a peak in June and July (Mansfield and Gajadhar 2004). In countries such as Haiti (Eberhard, Nace, and Freeman 1999), Peru (Bern et al. 2002), and Turkey (Turgay et al. 2007), the frequency of cyclosporiasis incidence peaks during seasons with less rainfall. Many times, the conditions that aid in Cyclospora propagation are also conducive for fruit and vegetable production. These conditions tend to occur at varying times in different regions of the world. When fruit and vegetable production is out of season in the United States, it is often in season in another country. The United States imports produce to fill domestic consumer demand that happens mostly during these off-seasons. If a producing country does not adhere to adequate sanitary practices (for example, if crops are irrigated with untreated water, or if employees are not required to adhere to hygienic and sanitary practices), the risk of infestation with $C$. cayetanensis oocysts increases. This has led to multiple domestic outbreaks of gastroenteritis mostly linked to imported goods contaminated with Cyclospora (Hall, Jones, and Herwaldt 2011).

Based on the necessary conditions for the oocysts to mature and become infectious, it is unlikely that transmission occurs immediately after harvest. This may mean that exported products that are contaminated during harvesting may be more likely to transmit the infection than those that are harvested and sold locally. Increasing globalization of the food supply means that all countries importing fresh produce from countries where Cyclospora is endemic are potentially at risk (Mansfield and Gajadhar 2004).

\section{What are the symptoms associated with Cyclospora cayetanensis?}

Usually, symptoms begin about one week after ingestion of contaminated food or water. Such symptoms may include:

- Frequent watery diarrhea ( 6 stools/day, possibly explosive)

- Substantial weight loss

- Bloating

- Anorexia

- Fatigue

- Abdominal cramps

- Constipation

- Loss of appetite

- Low-grade fever

Some cases are asymptomatic (without symptoms). The disease usually is self-limiting (symptoms go away after a few days without medical intervention) and typically is not fatal, although there can be a relapse (symptoms return). In severe cases, symptoms can last more than a month if left untreated (Chacín-Bonilla 2017; Ortega and Sanchez 2017).

\section{What risk groups are more likely to be affected by Cyclospora cayetanensis?}

As with many foodborne pathogens, certain populations are at higher risk of becoming sick. Typically, in developed countries, individuals at very young and very old ages are at higher risk (Chacín-Bonilla 2017). Recent tourists and former residents of less-developed countries where the disease is established are also at higher risk (Torres-Slimming et al. 2006). Young children are most likely to develop symptoms, while older children and adults tend to be more resistant to infection or asymptomatic (Chacín-Bonilla 2017). In the United States, foodborne outbreaks of cyclosporiasis have been linked to various types of imported fresh produce (CDC 2018a).

\section{What foods are associated with cyclosporiasis?}

In most instances, outbreaks have been associated with consumption of raw produce. Several types of fresh produce have been implicated as vehicles of transmission. In June and July of 2018, romaine lettuce used in a popular 
hamburger chain restaurant's salad mix resulted in confirmed cases of Cyclospora infection in the United States; of these, 246 cases were reported in Illinois (CDC 2018a). In July and August of 2018, 631 cases were reported across 25 states. Investigations performed by local public health officials, the US Food and Drug Administration (FDA), and the Centers for Disease Control and Prevention (CDC) implicated two separate vehicles of infection: salad mix produced by Taylors Farms de Mexico and fresh cilantro from Pueblo, Mexico (CDC 2013). Additionally, imported fresh raspberries, snow peas, Thai basil, cilantro, and mesclun lettuce have all been implicated in US outbreaks (Chacín-Bonilla 2010; Chacín-Bonilla 2017; Hall, Jones, and Herwaldt 2011). The implication of multiple vehicles of infection in the United States since the mid-2000s highlights the need for prevention and control measures to ensure the safety of produce that is eaten raw and the need for an improved understanding of the epidemiology of Cyclospora. Table 1 outlines recent foodborne Cyclospora outbreaks in the United States.

\section{Prevention of Cyclosporiasis}

Based on current information available, Cyclospora may be resistant to routine chemical disinfection methods such as those using chlorine. However, farmers, restaurants, retailers, and consumers should still follow basic produce and food safety practices as described below.

\section{At the Farmer's Level}

Controlling sources of contamination in the field, in the packinghouse, and from farm workers is key to preventing illnesses. Good hygiene (including proper handwashing) is a critical component of ensuring the safety of fresh produce, but by itself it may not be enough to prevent infected employees from contaminating fresh produce. Considering the varying cultural practices of farm workers, farm management should train workers on how to properly use toilet facilities provided by the farm, including the sanitary disposal of toilet paper. Make sure toilets and handwashing stations are well maintained, cleaned, and emptied in a way that prevents human waste and/or gray water from contaminating fresh produce, food contact surfaces, and/or adjacent areas. Train farm workers to self-report applicable symptoms and illnesses to the appropriate responsible person, and don't allow ill farm workers to handle fresh produce or touch food contact surfaces. If utilizing a contractor for cleaning and sanitizing the portable toilets, consider using reputable companies that dispose of human waste into an adequate sewage system or through other adequate means. Municipal wastewater treatment incorporates disinfection processes designed to kill or inactivate C. cayetanensis. Farms should avoid using untreated manure as a fertilizer for fruits and vegetables. The USDA National Organic Program specifies regulations regarding the time associated with composted manure under section 205, subsection 203 (http://www.ams.usda. gov/AMSv1.0/getfile?dDocName=STELPRDC5087165). The FSMA Produce Safety Rule requires that personnel on farms use hygienic practices $(\$ 112.32)$ and that ill employees are excluded from handling fresh produce and food contact surfaces $(\$ 112.31)$.

\section{At Restaurant and Retailer's Level}

Retailers, restaurants, and other food-service operators should always practice safe food handling and preparation measures. It is recommended that they wash and sanitize utensils and surfaces before and after handling food. Wash and sanitize display cases and refrigerators where potentially contaminated products are stored. Wash and sanitize cutting boards, surfaces, and utensils used to prepare, serve, or store potentially contaminated products. Wash hands with warm water and soap following the cleaning and sanitation process. Regular frequent cleaning and sanitizing of food contact surfaces and utensils used in food preparation may help to minimize the likelihood of cross-contamination.

\section{At Consumer Level}

Wash the inside walls and shelves of the refrigerator, cutting boards, and countertops, then sanitize them with a solution of one tablespoon of food-grade, unscented chlorine bleach to one gallon of hot water, and dry with a clean cloth or paper towel that has not been previously used (FDA 2018). Wash hands with warm water and soap for at least 20 seconds before and after handling food. Wipe up spills in the refrigerator immediately and clean the refrigerator regularly. Always wash hands with warm, soapy water following the cleaning and sanitization process. Persons who think they might have become ill from eating potentially contaminated foods should consult their health-care provider.

The CDC (2018b) recommends that fruits and vegetables that are labeled "prewashed" do not need to be washed again at home. Scrub firm fruits and vegetables, such as melon and cucumbers, with a clean produce brush. Cut away any damaged or bruised areas of the fruits and vegetables before preparing and eating. Store cut, peeled, or cooked fruits and vegetables refrigerated as soon as possible, or within two hours. Store fruits and vegetables away from raw meat, poultry, and seafood (CDC 2018b). 
Practicing all these will decrease but will not eliminate the risk of Cyclospora transmission. The theoretical infective dose for Cyclospora is one infective oocyst, though likelihood of infection increases with the quantity of sporulated oocysts ingested (Hall, Jones, and Herwaldt 2011). Travelers to resource-poor countries or other areas with substandard effluent treatment facilities should be advised to follow precautions specified by the CDC's "Yellow Book," Traveler's Health (CDC 2017)

Individuals should be aware that the only way to prevent cyclosporiasis is to avoid ingesting contaminated products, as there is no vaccination for this disease. Most people who contract cyclosporiasis are treated with a combination of two antibiotics, trimethoprim-sulfamethoxaole (TMPSMX), also known as Bactrim/Septra/Cotrim (CDC 2018a). People who have diarrhea should also rest and drink plenty of fluids (Ortega and Sanchez 2010). However, those with sensitivities to sulfa drugs and immunocompromised individuals will need to consult with their medical professionals about alternative methods of treatment (Ortega and Sanchez 2010).

\section{Additional Measures to Minimize Risk}

- Use and drink purified water (potable water, bottled water, etc.), especially when visiting developing countries or where water supplies are under less-rigorous sanitary programs. Water can be made safe by boiling, if necessary.

- Because children in endemic locations are more susceptible to infection, shed higher number of oocysts, and have infections with longer durations, they should not be involved in work that brings them in contact with fresh produce (Mansfield and Gajadhar 2004).

In an ever more globalized economy, the potential of produce being sourced from countries that don't follow the same strict food safety practices will remain. The removal and/or inactivation of Cyclospora oocysts from fresh produce remains challenging since much of our produce is consumed raw. Without a kill step, it seems unlikely that one treatment process would be suitable, effective, and/or cost effective in eliminating Cyclospora from fresh produce that is intended to be consumed raw. While irradiation can be effective in inactivating Cyclospora oocysts, this practice still hasn't gained wide acceptance from consumers (Ortega and Sanchez 2010). Currently, the best method for reducing the risk of Cyclospora infections remains the use of safe farming practices such as the Produce Safety Rule (United States only), GlobalG.A.P., and Good Agricultural
Practices (Mansfield and Gajadhar 2004). The new Food Safety Modernization Act (FSMA) has as one of its tenets the Foreign Supplier Verification Program, which sets standards for any company importing fresh produce into the United States. Under this program, foreign suppliers would have to meet the standards outlined in the Produce Safety Rule in order to import produce.

\section{References}

Bern, C., Y. Ortega, W. Checkley, J.M. Roberts, A.G. Lescano, L. Cabrera, M. Verastegui, R.E. Black, C. Sterling, and R.H. Gilman. 2002. Epidemiological differences between cyclosporiasis and cryptosporidiosis in Peruvian children. Emerging Infectious Diseases 8:581-585.

Centers for Disease Control and Prevention (CDC). 2013. Notes from the field: Outbreaks of cyclosporiasis-United States, June-August 2013. Morbidity and Mortality Weekly Report 62:862-862.

Centers for Disease Control and Prevention (CDC). 2018a. Multistate Outbreak of Cyclosporiasis Linked to Fresh Express Salad Mix Sold at McDonald's Restaurants United States, 2018a. Available at: https://www.cdc.gov/ parasites/cyclosporiasis/outbreaks/2018/b-071318/index. html. Accessed on January 28, 2019.

Centers for Disease Control and Prevention (CDC). $2018 \mathrm{~b}$. Parasites - Cyclosporiasis (Cyclospora infection). Available at: https://www.cdc.gov/parasites/cyclosporiasis/index. html. Accessed on January 26, 2019.

Centers for Disease Control and Prevention (CDC). 2017. Traveler's health. Chapter 3; Infectious Diseases Related to Travel. Available at: https://wwwnc.cdc.gov/travel/ yellowbook/2018/infectious-diseases-related-to-travel/ cyclosporiasis. Accessed on January 28, 2019.

Chacín-Bonilla, L. 2010. Epidemiology of Cyclospora cayetanensis: A review focusing in endemic areas. Acta Tropica 115:181-193.

Chacín-Bonilla, L. 2017. Cyclospora Cayetanensis. In: J.B. Rose and B. Jiménez-Cisneros, (eds) Global Water Pathogens Project. http://www.waterpathogens.org (J.S Meschke, and R. Girones (eds) Part 3 Viruses) http://www. waterpathogens.org/book/cyclospora-cayetanensis Michigan State University, E. Lansing, MI, UNESCO. 
Eberhard, M. L., E. K. Nace, and A. R. Freeman. 1999. Survey for Cyclospora cayetanensis in domestic animals in an endemic area in Haiti. The Journal of Parasitology 85:562.

Hall, R.L., J.L. Jones, and B.L. Herwaldt. 2011. Surveillance for laboratory-confirmed sporadic cases of cyclosporiasisUnited States, 1997-2008. Morbidity and Mortality Weekly Report. 60:1-13.

Mansfield, L.S. and A.A. Gajadhar. 2004. Cyclospora cayetanensis, a food-and waterborne coccidian parasite. Veterinary Parasitology 126:73-90.

Ortega, Y.R., and L. J. Robertson. 2017. Cyclospora cayetanensis as a foodborne pathogen. Springer, Cham.

Ortega, Y.R. and R. Sanchez. 2010. Update on Cyclospora cayetanensis, a food-borne and waterborne parasite. Clinical Microbiology Reviews 23:218-234.

Torres-Slimming, P.A., C.C. Mundaca, M. Moran, J. Quispe, O. Colina, D.J. Bacon, A.G. Lescano, R.H. Gilman, and D.L. Blazes. 2006. Outbreak of cyclosporiasis at a naval base in Lima, Perú. The American Journal of Tropical Medicine and Hygiene 75:546-548.

Turgay, N., A. Yolasigmaz, D. D. Erodogan, F.Y. Zeyrek, and A. Uner. 2007. Incidence of cyclosporiasis in patients with gastrointestinal symptoms in western Turkey. Medical Science Monitor 13:CR34-CR39.

U.S. Food \& Drug Administration (FDA). 2018. Division of foodborne pathogens. Fact sheet: Cyclospora. Available at: https://www.fda.gov/Food/FoodborneIllnessContaminants/ Pathogens/ucm610936.htm\#Cyclosporiasis. Accessed on January 28, 2019.

\section{Resources}

U.S. Food \& Drug Administration (FDA). 2018. Division of foodborne pathogens. Fact sheet: Cyclosporiasis and fresh produce. Accessed on January 28, 2019. https://www. fda.gov/Food/FoodborneIllnessContaminants/Pathogens/ ucm621533.htm.

Centers for Disease Control and Prevention (CDC), Division of Parasitic Diseases. August 2018. "Fact sheet: Parasites - Cyclosporiasis (Cyclospora Infection)." Accessed on January 28, 2019. http://www.cdc.gov/parasites/cyclosporiasis/index.html.
Food Safety and Inspection Services, USDA. September 2017. Parasites and foodborne illness. Accessed on January 28, 2019. http://www.fsis.usda.gov/wps/ portal/fsis/topics/food-safety-education/get-answers/ food-safety-fact-sheets/foodborne-illness-and-disease/ parasites-and-foodborne-illness/. 
Table 1. Foodborne outbreaks of Cyclospora in the United States since 2008.

\begin{tabular}{|c|c|c|c|}
\hline Month/Year & Location & Number of Cases & Food/Source \\
\hline March 2008 & Wisconsin & 4 & Sugar snap peas \\
\hline July 2008 & California & 45 & Raspberries/Blackberries \\
\hline June 2009 & Washington, DC & 34 & ND \\
\hline June 2011 & Florida & 12 & ND \\
\hline July 2011 & Georgia & 88 & ND \\
\hline June-July 2012 & Texas & 16 & ND \\
\hline June 2013 & lowa; Nebraska & 161 & Bagged salad mix (Mexico) \\
\hline June-July 2013 & Texas & 38 & Cilantro (Mexico) \\
\hline July 2013 & Wisconsin & 8 & Berry salad \\
\hline June 2014 & Michigan & 14 & ND \\
\hline June-July 2014 & Texas & 26 & Cilantro (Mexico) \\
\hline July 2014 & South Carolina & 13 & \\
\hline May-July 2014 & Georgia; Texas; Wisconsin & 90 & Cilantro (Mexico) \\
\hline June-July 2016 & Texas & 6 & Carrots or green cabbage \\
\hline June-July 2018 & Minnesota; Wisconsin; Michigan; lowa & $237^{*}$ & Produce vegetable trays \\
\hline July-August 2018 & $\begin{array}{l}\text { Illinois; lowa; Missouri; Ohio; South } \\
\text { Dakota; Wisconsin; Minnesota; } \\
\text { Kentucky; Indiana }\end{array}$ & $436^{*}$ & Carrots in salad mix \\
\hline $\begin{array}{l}\text { (Sources: CDC 2018a, } \\
\mathrm{ND}=\text { Not determinec } \\
\text { *More details availab }\end{array}$ & 018b, Ortega and Robertson 2017) & 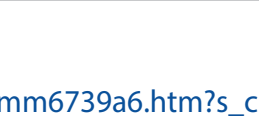 & $=\mathrm{mm6739a6} w$ \\
\hline
\end{tabular}

